\title{
Currículo, poder e a política do livro didático de geografia no Brasil
}

\author{
Márcio Abondanza Vitiello' (D) \\ Núria Hanglei Cacete" (D)
}

\section{RESUMO}

Neste terceiro decênio do século XXI, período no qual ações neoconservadoras buscam eufemizar, distorcer e invisibilizar temas sociais, políticos, econômicos e culturais, as discussões sobre currículo escolar e políticas públicas educacionais tornam-se centrais. Inicialmente, promovemos uma análise da relação entre currículo e poder, no qual diferentes atores exprimem suas intencionalidades, sobrelevando alguns temas e subjazendo outros. Em seguida, abordamos o papel do livro didático no currículo escolar, especialmente no âmbito do ensino de Geografia, em uma perspectiva que ora relativiza, ora prioriza o uso desses manuais nos processos de ensino e aprendizagem. Por fim, buscamos compreender as políticas públicas relativas ao livro didático e as recentes ações no campo do currículo, consubstanciadas na Base Nacional Comum Curricular (BNCC) e na Reforma do Ensino Médio.

\section{PALAVRAS-CHAVE}

Base Nacional Comum Curricular; Programa Nacional do Livro Didático; política educacional. 


\title{
CURRICULUM, POWER AND GEOGRAPHY TEXTBOOK POLICY IN BRAZIL
}

\begin{abstract}
In this third decade of the $21^{\text {st }}$ century, a period in which neoconservative actions seek to euphemize, distort and make social, political, economic and cultural issues invisible, discussions about school curriculum and public educational policies become central. Initially, we promoted an analysis of the relationship between curriculum and power, in which different actors express their intentions, highlighting some themes and underlying others. Then, we approach the role of the textbook in the school curriculum, especially in the field of Geography teaching, in a perspective that sometimes relativizes, sometimes prioritizes the use of these manuals in the teaching and learning processes. Finally, we seek to understand public policies related to textbooks and the recent actions in the field of curriculum, embodied in the Common National Curriculum Base (Base Nacional Comum Curricular - BNCC) and in the High School Reform.

KEYWORDS

Common National Curriculum Base; National Textbook Program; educational policies.
\end{abstract}

\section{CURRÍCULUM, PODER Y POLITICA DE LIBROS DE TEXTO DE GEOGRAFÍA EN BRASIL}

\section{RESUMEN}

En esta tercera década del siglo XXI, un período en el que las acciones neoconservadoras buscan eufemizar, distorsionar y hacer invisibles los problemas sociales, políticos, económicos y culturales, las discusiones sobre los planes de estudio escolares y las políticas educativas públicas se vuelven centrales. Inicialmente, promovimos un análisis de la relación entre el currículum y el poder, en el que diferentes actores expresan sus intenciones, destacando algunos temas y otros subyacentes. Luego, abordamos el papel del libro de texto en el currículo escolar, especialmente en el campo de la enseñanza de Geografía, en una perspectiva que a veces se relativiza, a veces prioriza el uso de estos manuales en los procesos de enseñanza y aprendizaje. Finalmente, buscamos comprender las políticas públicas relacionadas con los libros de texto y las acciones recientes en el campo del currículo, plasmadas en la Base Nacional Curricular Común (BNCC) y en la Reforma de la Escuela Secundaria. 


\section{CURRÍCULO E PODER}

O currículo surge como uma necessidade social, sobretudo econômica e cultural, expressando relações de poder, ideologias, valores e concepções distintas em relação ao processo educacional. Em uma perspectiva pós-estruturalista, Silva (2003) aponta que, antes de tudo, o currículo deve ser entendido como uma questão de poder, lembrando que "selecionar é uma operação de poder. Privilegiar um tipo de conhecimento é uma operação de poder" (Silva, 2003, p. 16).

Esse poder de seleção é definido em meio a um amplo campo de discussões e debates no âmbito da Sociologia do Currículo. De acordo com Bernstein (1993), diversos agentes atuam na produção e reprodução do discurso pedagógico, dentre os quais o Estado, o professor, a família, a comunidade, os editores e os autores de livros didáticos, as universidades, entre outros. Nesse caso, o campo de recontextualização oficial é aquele criado e dominado pelo Estado e seus agentes, enquanto o de recontextualização pedagógica é constituído a partir dos educadores e das universidades. Assim o campo recontextualizador pedagógico:

1. Abarca a universidade e os departamentos de educação, centros universitários de educação e suas pesquisas e fundações privadas; 2. Inclui publicações especializadas em educação: semanários, revistas, assim como editoriais, seus leitores e anunciantes; 3 . Pode estender-se a campos não especializados no discurso educativo e suas práticas, mas capazes de exercer influências, tanto no Estado e seus diferentes órgãos como sobre lugares, agentes e práticas especiais no âmbito da educação. (Bernstein, 1993, p. 197)

Para Bernstein (1993), de acordo com as teorias de reprodução cultural, as relações de poder existentes na sociedade são transportadas para o interior da escola e reproduzidas por esta. Dessa forma, tanto a escola como os professores teriam uma atuação mais acentuada na reprodução do discurso pedagógico. Bernstein (1993) salienta ainda que ambos os campos de recontextualização - o oficial e o pedagógico - são afetados pelos campos de produção (economia) e de controle simbólico.

Ao discorrer sobre o currículo com base em práticas diversas, Sacristán (1998) coloca que a escola, por meio do ensino, transmite certa cultura e se vê submetida às transformações de acordo com os processos de seleção, formulação (confecção do currículo) e de realização (ensino).

Dessa forma, o autor discorre que o currículo é formulado por diferentes agentes, que o planejam fora do meio em que se realiza de forma prática e afirma que "a cultura selecionada e organizada dentro do currículo não é a cultura em si mesma, mas uma versão escolarizada em particular" (Sacristán, 1998, p. 128). Afirma ainda que a cultura contida no currículo é um saber "curricularizado", e que o currículo, portanto, possui uma cultura própria, que presta um serviço à socialização e à reprodução.

Outro importante conceito discutido por Sacristán (1998) é o de currículo oculto. Esse conceito, cunhado por Philip Jackson (1968), é definido como uma dimensão não evidente, contraposta ao "currículo oficial", constituído nas relações 
sociais, na distribuição do tempo e do espaço, nas relações de autoridade, no uso de prêmios e castigos, no clima de avaliação, entre outros. Além disso, Sacristán (1998) afirma que as normas de comportamento escolar não foram geradas como algo autônomo, mas têm relação com valores sociais e com formas de entender o papel dos indivíduos nos processos sociais. E completa:

As análises mais objetivas sobre o currículo oculto provêm do estudo social e político dos conteúdos e das experiências escolares. Hábitos de ordem, pontualidade, correção, respeito, competição-colaboração, docilidade e conformidade são, entre outros, aspectos inculcados consciente ou inconscientemente pela escola que denotam um modelo de cidadão/dã. (Sacristán, 1998, p. 132)

Para esse autor, esses valores são também elementos de uma socialização oculta e a escola não está isolada dos conflitos sociais externos a ela. Assim, as mensagens derivadas do currículo oculto não são alheias aos conflitos sociais: os papéis do sexo na cultura, o exercício da autoridade, os mecanismos de distribuição da riqueza, as posições dos grupos sociais, políticos, raciais e religiosos.

Um exemplo é o da distinção no tratamento entre meninos e meninas, ao imporem determinados padrões de comportamento e conduta de acordo com o gênero. Ao se tornarem manifestações de um conflito social, eles podem ser analisados por sua dimensão oculta, mas também explícita. Para Sacristán (1998), certos casos de abandono e de fracasso escolar são manifestações passiva e ativa às normas do currículo oculto, ou ao fracasso da socialização que impõe.

Ao entender o currículo como um processo e não apenas como uma lista de conteúdos definidos a priori por uma equipe de especialistas que defendem a classe dominante, Sacristán (1998) amplia o número de agentes que atuam na elaboração, implantação e desenvolvimento do currículo, o que vem ao encontro da própria concepção e elaboração de um livro didático, por exemplo. Para Sacristán (1998, p. 140), "se a relação entre currículo e prática escolar não é mecânica, mas mediatizada por práticas diversas, essas práticas são elementos da reprodução ou, pelo contrário, elementos potenciais de resistência à mesma".

Para justificar sua posição, Sacristán (1998) critica autores que subjugam a cultura escolar ao domínio de uma classe dominante, pois tal visão ignora a resistência dos grupos de professores(as) e de alunos(as) às tentativas de imposição cultural, além de desconsiderar de que as escolas são lugares de produção cultural.

Apple (2006, p. 37) afirma que, para além da propriedade econômica, há a propriedade simbólica, ou o capital cultural, que é preservado e distribuído pelas escolas. Assim, segundo Apple (2006), é possível entender como as escolas "criam e recriam formas de consciência que permitem a manutenção do controle social sem a necessidade de os grupos dominantes terem de apelar a mecanismos abertos de dominação". A questão ideológica presente no currículo também é amplamente questionada por Michael Apple (2006, p. 40):

$\mathrm{O}$ ato fundamental envolve tornar problemáticas as formas de currículo encontradas nas escolas, de maneira que seu conteúdo ideológico latente possa 
ser desvelado. As questões sobre tradição seletiva, tais como se apresentam a seguir precisam ser levadas a sério. De quem é o conhecimento? Quem o selecionou? Por que é organizado e ensinado dessa forma? $\mathrm{E}$ a este grupo em particular? Apenas formular essas questões não é, porém, suficiente. Orientamo-nos, também pela tentativa de conectar essas investigações a concepções correntes de poder econômico e social e de ideologias. Dessa forma, podemos começar a ter uma apreciação mais concreta das conexões entre poder econômico e político e o conhecimento que é disponibilizado (e o que não é disponibilizado) aos alunos.

Devemos entender que a ideologia é um conceito complexo. Partindo de uma conceptualização ampla, na qual ela é definida como uma falsa consciência que deforma a própria realidade social, atendendo aos interesses da classe dominante, Apple (2006) alerta sobre a necessidade de entender a ideologia atrelada ao conceito de hegemonia. Para isso, ele irá se amparar nos estudos de Antônio Gramsci e Raymond Willians para afirmar que

a hegemonia se refere não à acumulação de significados que estão em um nível abstrato em algum lugar "da parte superior de nossos cérebros". Ao contrário, refere-se a um conjunto organizado [...], eficaz e dominante de significados, valores e ações que são vividos. (Apple, 2006, p. 39)

Tal visão aproxima-se da discussão conceitual feita por John Thompson (1990, p. 76), para quem "estudar a ideologia é estudar as maneiras como o sentido serve para estabelecer e sustentar relações de dominação". Ou seja, o que interessa para Thompson (1990) não é a verdade ou a falsidade das formas simbólicas, e sim a maneira como essas formas servem para estabelecer e sustentar relações de dominação.

Importa assinalar, ainda, onde se encontram os principais pontos de apoio para a investigação curricular segundo Sacristán (1998, p. 138, grifos nossos):

Nos documentos curriculares (o currículo prescrito e regulado); na programação ou nos projetos pedagógicos das escolas (o currículo no contexto das práticas organizativas); nas tarefas de aprendizagem ou planos de aulas dos professores (o currículo em ação); nos exames ou avaliações e nos livros didáticos (livros-textos, guias didáticos e materiais diversos), esse último classificado como "o currículo criado para ser consumido pelos professores e alunos.

\section{CURRÍCULO E LIVRO DIDÁTICO}

É nesse contexto de discussão sobre o currículo que o livro didático se insere. De acordo com Barreto (1998), embora a partir de meados da década de 1980, uma ampla gama de propostas e documentos oficiais tenha sido prescrita, essa pluralidade e aparente diversidade de orientações curriculares no 
país acabaram se diluindo, porque o que marca o currículo nas salas de aulas é frequentemente o grande atrelamento dos professores aos livros didáticos que adotam. Essa correlação entre currículo oficial e livro didático encontra respaldo em Apple (2002, p. 65).

Quer se queira, quer não, na maioria das escolas americanas, não se define o currículo por disciplinas nem por programas sugeridos, mas sim através de um determinado artefacto - o manual estandartizado e específico para cada nível de matemática, leitura, estudos sociais, ciências (quando se ensinam), entre outros.

O livro didático, manual ou compêndio escolar, é um objeto de estudo complexo que reúne vários elementos para a sua análise. Constitui-se em uma obra pedagógica que reflete os conhecimentos científicos e características culturais de uma dada sociedade em determinado período histórico e espaço geográfico. Além disso, acompanha os processos técnicos e mercadológicos da produção editorial, sendo uma das vertentes curriculares no ambiente escolar.

Choppin (2004) aponta que os livros didáticos exercem quatro funções essenciais: a referencial, ou curricular, na qual se observa uma tradução fiel do programa de ensino e um suporte privilegiado dos conteúdos educativos; instrumental, pois coloca em prática métodos de aprendizagem, na maioria das vezes com exercícios e atividades; ideológica e cultural, pois é um importante vetor de disseminação da língua, mas também dos valores das classes dirigentes; e documental, pois compõem um conjunto de documentos, textuais ou icônicos, que podem contribuir com o desenvolvimento do espírito crítico do aluno. Ademais, Choppin (2004) não vê o livro didático como o único objeto responsável pela formação dos estudantes.

O livro didático não é, no entanto, o único instrumento que faz parte da educação da juventude [...]. Estes outros materiais didáticos podem fazer parte do universo dos textos impressos (quadros ou mapas de parede, mapas múndi, diários de férias, coleções de imagens, [...] enciclopédias escolares...) ou são produzidos em outros suportes (audiovisuais, softwares didáticos, CD-Rom, internet, etc.). [...] O livro didático, em tais situações, não tem mais existência independente, mas torna-se um elemento constitutivo de um conjunto multimídia. (Choppin, 2004, p. 553)

Ainda sobre o aspecto multifacetado do livro didático, Bittencourt (2010) também irá pontuar algumas características importantes dos manuais escolares, tais como ser uma mercadoria, logo, um produto que obedece às lógicas de mercado; ser uma produção coletiva que conta com, além do autor, a participação de editores, técnicos gráficos, ilustradores e programadores visuais; um depositário de conteúdos escolares, suporte das propostas curriculares; um instrumento pedagógico, no qual se inserem não apenas os conteúdos das disciplinas, mas como eles devem ser ensinados; e, por fim, o fato de ser um veículo portador de um sistema de valores, de uma ideologia, de uma cultura. 
A complexidade da natureza desse produto cultural explica com maior precisão o predomínio que exerce como material didático no processo de ensino e na aprendizagem da disciplina, qualquer que seja ela. $\mathrm{O}$ livro didático tem sido, desde o século XIX, o principal instrumento de trabalho de professores e alunos, sendo utilizado nas mais variadas salas de aula e condições pedagógicas, servindo como mediador entre a proposta oficial do poder expressa nos programas curriculares e o conhecimento escolar ensinado pelo professor. (Bittencourt, 2010, p. 72)

Embora, muitas vezes, o livro didático tenha tendência a se transformar em um objeto padronizado, com linguagem simplificada que impeça reflexões ou discordâncias por parte do leitor, o uso que os professores e alunos fazem desse material sofre variações e pode se tornar um instrumento de trabalho mais adequado às necessidades de um ensino autônomo.

Sene (2014), em defesa do uso do livro didático, argumenta que os professores, por melhor que fossem suas formações, não seriam capazes de produzir um material didático consistente, mesmo porque, na maioria das vezes com baixos salários e obrigados a lecionar muitas aulas, lhes falta tempo. Soma-se a isso o fato de que, conforme dados do Censo Escolar de 2015, cerca de 41\% dos professores que lecionavam Geografia no Ensino Médio e 70\% nos anos finais do Ensino Fundamental (Redação, 2017), no Brasil, não tinham formação na área. Para eles, portanto, o livro didático será um importante instrumento para encontrar textos, atividades interdisciplinares, sugestões de leituras complementares, entre outros recursos que poderão facilitar o trabalho docente ${ }^{1}$.

Se, por um lado, esse fato pode significar uma facilidade para o professor, por outro, também pode representar algumas limitações, como tornar-se dependente de atributos, valores, conteúdos e métodos restritos à obra didática. Como afirma Oliva (1999, p. 40), "mesmo com as mudanças em direção à renovação, os livros didáticos, em sua maioria, ainda resistem e mantêm um formato jornalístico e antiacadêmico".

Sene (2014), por seu turno, contesta esse posicionamento soberano imposto pela Geografia acadêmica e opõe-se à ideia de que livros didáticos sejam uma mera transposição didática ${ }^{2}$ do conhecimento acadêmico para o escolar.

Mesmo hoje em dia grande parte do conteúdo que consta dos livros didáticos não têm nada de transposição. Com base em minha experiência como autor, constato que não conseguiria escrever livros didáticos se tivesse que me ancorar apenas na

1 De acordo com levantamento do "QEdu: Aprendizado em Foco", uma parceria entre a Meritt e a Fundação Lemann, 98\% dos professores afirmam utilizar os livros didáticos, contra $85 \%$ que dizem fazer uso de jornais e revistas e $62 \%$ da internet. Questionários aplicados: 304.412 (QEdu, 2013).

2 O conceito de transposição didática foi cunhado em 1975 por Michel Verret, mas se popularizou por meio da obra La transposición didáctica: del saber sabio al saber enseñado, do educador francês Yves Chevallard (1991), publicado em 1985 em francês. 
produção da "comunidade científica da Geografia" [...]. Para elaborá-los utilizo muitos dados, informações e conhecimentos produzidos por instituições não acadêmicas, sobretudo os disponíveis em relatórios e documentos de instituições nacionais - como o IBGE, IPEA, INPE e diversos órgãos das três esferas de governo - e internacionais - como as agências da ONU (PNUD, UNCTAD, UNIDO, FAO etc.), o Banco Mundial, a OMC, o FMI, a OCDE, entre outras - além de ONGs, do país e do exterior. (Sene, 2014, p. 35)

Essa referência encontra respaldo na fala de outro autor de livros didáticos de Geografia, o professor Elian Allabi Lucci, conforme entrevista transcrita em Munakata (1997, p. 191):

A vida de autor profissional é de muita leitura, de muita pesquisa sobre vários aspectos e muitas entrevistas. No meu caso, Geografia, eu tenho que sair a campo para pesquisar, para entrevistar pessoas. Então, o nosso tempo é todo empregado hoje nisso. Hoje, no meu trabalho eu viajo, fotografo, entrevisto, pesquiso. Vou buscar um conhecimento mais concreto da realidade.

Deve-se realçar que o livro didático exerceu um papel fundamental na consolidação do ideário de Estado nacional a partir do século XIX. Por meio dele, era possível disseminar valores patrióticos, impor um idioma hegemônico e fazer valer o discurso oficial. Os primeiros autores de livros didáticos no Brasil, ainda no período imperial, pertenciam a uma elite intelectual e tinham estreitas ligações com a política educacional do Estado. Muitos deles eram oriundos da Escola Militar, fundada em 1810; do Colégio Pedro II, de 1837 e do Instituto Histórico e Geográfico Brasileiro (IHGB), fundado um ano depois; todos sediados na então capital nacional, a cidade do Rio de Janeiro.

De acordo com Bittencourt (2004), ainda no final do século XIX surgiu uma segunda geração de autores de livros didáticos. Esses, por sua vez, possuíam maior experiência pedagógica e lidavam com a formação de professores. Esse grupo também era mais heterogêneo, pensando suas obras para um público mais amplo, incluindo mulheres e jovens de classes menos favorecidas.

Houve também o surgimento de autores que se opunham à influência direta do Estado e da igreja católica em suas obras, pregando um ensino positivista, sem dogmas e pautado na laicidade e na "neutralidade".

Apesar de os livros didáticos serem amplamente difundidos em grande parte das instituições de ensino mundiais há cerca de dois séculos, foi notadamente a partir da década de 1970 que alguns pesquisadores passaram a analisar mais criticamente estas obras.

Uma obra de referência, cuja primeira edição data de 1972, mas que vem sendo reeditada até os dias de hoje, é Mentiras que parecem verdades ${ }^{3}$, do linguista e escritor italiano Umberto Eco (1932-2016) e da educadora Mariza Bonazzi (1927-2015).

3 Versão italiana é denominada I pampini bugiardi (Rimini: Guaraldi, 1972). 
Nesse livro, os autores reúnem uma série de textos extraídos de manuais escolares italianos para demonstrar o caráter ideológico alinhado a uma sociedade autoritária, repressiva, conservadora e reacionária. Os pobres, o trabalho, as raças e os povos terrestres, entre outros, são alguns dos temas utilizados para a análise. Para Eco e Bonazzi (1980, p. 16), "os livros de leitura contam mentiras, educam os jovens para uma falsa realidade, enchem sua cabeça com lugares-comuns, com coisas chãs, com atitudes não críticas".

É evidente que um inconsciente racismo penetra os textos escolares, mesmo quando a finalidade aparente da estória ou da poesia é a de apresentar à criança a realidade das diferenças étnicas, através de uma compreensão e uma simpatia um pouco vagas. [...] é colocada em relevo somente a "diversidade" das outras raças e sempre com uma curiosidade teratológica, ao passo que os outros textos intervêm para reforçar no pequeno leitor a ideia de que ele pertence a uma raça melhor, a uma pátria com as montanhas mais belas e os prados mais verdes do que as outras pátrias. (Eco e Bonazzi, 1980, p. 53)

No Brasil, principalmente a partir da década de 1980, vários autores passaram a se dedicar a essa análise, dentre os quais Molina (1987), Freitag, Motta e Costa (1989), Munakata (1997, 2012), Bittencourt (2004, 2010) e Faria (2008) e Moreira (2014).

Moreira (2014, p. 97) coloca que os livros didáticos "expressam o modo como o ensino escolar dialoga de um lado com o fluxograma dos currículos universitários, onde é formado o professor escolar, [...] e de outro com os programas oficiais, obrigatórios e padronizados para todas as escolas do país”. Ao analisar algumas coleções de livros didáticos de Geografia a partir da década de 1930, esse pesquisador estabeleceu três fases de evolução do livro didático: a clássica, a transitória e a inovadora.

Na primeira fase, baseado nas coleções de Aroldo de Azevedo publicadas entre 1930 e 1970, Moreira (2014) situa que a estrutura das coleções agrupa os capítulos em três partes: "A base física", "A vida humana" e "A vida econômica", ao qual ele vai denominar de arquétipo-acamamento Natureza-Homem-Economia $(\mathrm{N}-\mathrm{H}-\mathrm{E})^{4}$. Na fase de transição ${ }^{5}$, na década de 1970, Moreira (2014) afirma que a paisagem desaparece como elemento de agregação e o mapa e a foto perdem a interação didática que tinham entre si e com o texto para tornarem-se recursos de ilustração; a formação dá lugar à informação.

4 Moreira (2014, p. 57) coloca que o modelo de sitio-situação-estrutura N-H-E é o "padrão de ciência que no correr do século XX se institui como discurso geográfico em todo o mundo". É o arquétipo estraboniano-ptolomeico, que se materializaram em livros universitários e escolares na Franca, nas obras: Tratado de geografia física (1920), de Emmanuel De Martonne; e Principios de geografia humana (1922), de Vidal de la Blache.

5 Como expoentes dessa fase, Moreira (2014) cita as autoras Guiomar Goulart de Azevedo e Zoraide Victorello Beltrame. 
A partir da década de 1980, segundo Moreira (2014), surgem obras didáticas inovadoras, com diferentes orientações intelectuais e com modelos didáticos plurais. Algumas dessas coleções - que tratam a Geografia do mundo em rede ${ }^{6}$ - pro- $^{-}$ movem a dissolução da linha N-H-E.

A geografia física setorial e a geografia humana setorial são também referências assistemáticas no misto físico-humano genérico que é o olhar tecnoambiental dominante. A geografia da população se dilui na dimensão antropossociologizada das manifestações de culturas e dos movimentos sociais. O repertório vocabular clássico do sítio, posição, situação, habitat, região, continente é substituído pelo de transversalidade que atravessa o tema da rede global. (Moreira, 2014, p. 121)

Com a introdução e a expansão do Programa Nacional do Livro Didático (PNLD), principalmente nas últimas duas décadas, o que se verificou foi um maior alinhamento dos materiais escolares com os pressupostos conceituais e metodológicos atrelados aos editais do programa.

Nesse momento, valemo-nos da conceituação de Munakata (1997, p. 100), para quem "o livro didático deve ser produzido em adequação a parâmetros que se imaginam constitutivos de um instrumento auxiliar do processo de ensino e aprendizagem"; o que implica uma série de critérios:

Conteúdo adequado ao currículo, legibilidade e inteligibilidade apropriados ao público-alvo; subdivisão da obra em partes, como texto propriamente dito, boxes, resumos, glossário, bibliografia, atividades e exercícios etc., segundo uma estrutura de organização adequada à aprendizagem; e, sobretudo, subordinação do estilo do texto e da arte gráfica a esse objetivo de servir de instrumento auxiliar de ensino/aprendizagem. (Munakata, 1997, p. 100)

\section{O ESTADO BRASILEIRO E O PROGRAMA NACIONAL DO LIVRO DIDÁTICO}

No Brasil, diferentes formas de análises, intervenções e até mesmo de censuras acompanham a história das políticas públicas com respeito ao livro didático. Embora os primeiros manuais escolares tenham sido publicados no período Imperial $^{7}$ e alguns

6 Nesta fase, Moreira (2014) cita as obras Geografias do mundo: redes e fluxos, de Marcos Bernardino de Carvalho e Diamantino Alves; Geografia, de Valquíria Pires Garcia e Beluce Belucci; Geografia, espaço e vivência, de Levon Boligian e Andressa Alves; Geografia e cidadania, de Eustáquio Sene e João Carlos Moreira; e Geografia, pesquisa e ação, de Ângela Corrêa Krajewski, Raul Borges Guimarães e Wagner Costa Ribeiro.

7 Embora o primeiro curso de Geografia no ensino superior tenha surgido apenas em 1934, na Universidade de São Paulo, a Geografia Escolar já era lecionada desde o início do século XIX, comprovado por meio da existência de manuais escolares como Corografia Brazilica, escrito pelo Padre português Ayres de Casal (1817) e Compendio elementar de Geographia Geral e Especial do Brasil, de Thomaz Pompêo de Souza Brasil (1851). 
processos de avaliação datem do século XIX, o controle oficial em nível federal iniciou-se na década de 1930, tendo sofrido alterações em diversos momentos históricos.

De acordo com Filgueiras (2011) é possível destacar quatro períodos relacionados a políticas nacionais voltadas aos livros didáticos anteriores ao atual PNLD. O primeiro processo foi instituído em 1938, com a criação da Comissão Nacional do Livro Didático (CNLD) e o segundo se deu na década de 1950, com a Campanha do Livro Didático e Manuais de Ensino (CALDEME). O terceiro e quarto períodos ocorreram durante a Ditadura Militar (1964-1985): em 1966, foi criada a Comissão do Livro Técnico e do Livro Didático (COLTED), extinta em 1971, quando surgiu o Instituto Nacional do Livro (INL), responsável pelo então Programa do Livro Didático. Importantes estudos sobre essas Comissões de Avaliação foram realizados por Munakata (1997), Gonçalves (2005), Krafzik (2006) e Ferreira (2008).

Durante o Estado Novo (1937-1945), na Era Vargas, o Decreto-lei no 1.006, de 30 de dezembro de 1938 (Brasil, 1939), estabeleceu as condições de produção, importação e utilização do livro didático, e tornou necessária uma autorização prévia para o livro entrar em circulação. Para avaliar as obras educativas foi criada a CNLD, formada por sete membros.

De acordo com o Capítulo IV, art. 20, seriam excluídos os livros que:

a) atente, de qualquer forma, contra a unidade, a independência ou a honra nacional;

b) contenha, de modo explícito ou implícito, pregação ideológica ou indicação da violência contra o regime político adotado pela Nação;

c) envolva qualquer ofensa ao Chefe da Nação, ou às autoridades constituídas, ao Exército, à Marinha, ou às demais instituições nacionais;

d) despreze ou escureça as tradições nacionais, ou tente deslustrar as figuras dos que se bateram ou se sacrificaram pela pátria;

e) encerre qualquer afirmação ou sugestão, que induza o pessimismo quanto ao poder e ao destino da raça brasileira;

f) inspire o sentimento da superioridade ou inferioridade do homem de uma região do país com relação ao das demais regiões;

g) incite ódio contra as raças e as nações estrangeiras;

h) desperte ou alimente a oposição e a luta entre as classes sociais;

i) procure negar ou destruir o sentimento religioso ou envolva combate a qualquer confissão religiosa;

j) inspire o desamor à virtude, induza o sentimento da inutilidade ou desnecessidade do esforço individual, ou combata as legítimas prerrogativas da personalidade humana. (Brasil, 1939, p. 277)

Ao examinar e julgar os livros, portanto, a CNLD promovia um controle político e ideológico das obras didáticas. Para Freitag, Motta e Costa (1989, p. 24), "a criação da Comissão insere-se em um rol de medidas visando à reestruturação e o controle ideológico de todo sistema”. Nesse período, atendendo aos interesses do 
Estado, foi introduzido o ensino de educação moral e cívica, expandidos os cursos profissionalizantes e extintas as escolas de imigrantes e o ensino de língua estrangeira, garantindo assim o espírito nacionalista desse governo. A partir da década de 1950 a CNLD teve suas funções reduzidas até ser extinta em 1969.

Em 1952, buscando renovar os métodos de ensino, atualizar e produzir novos livros didáticos, o educador baiano Anísio Teixeira, então diretor do Instituto Nacional de Pesquisas Educacionais (Inep) ${ }^{8}$, criou a Campanha do Livro Didático e Manuais de Ensino (CALDEME). Nesse período, a Campanha, além de melhorar a qualidade dos livros, efetivou a produção de manuais de ensino para o uso dos professores e a criação de uma biblioteca pedagógica.

No projeto da CALDEME, buscou-se dar maior autonomia aos autores; não havendo necessidade de seguir um programa oficial, apenas foi estabelecido um critério geral quanto aos conteúdos básicos necessários. As análises tinham por objetivo promover uma crítica construtiva que revelasse as qualidades e defeitos do programa e dos compêndios de Geografia e contribuísse para o seu aperfeiçoamento 9 . Nesse período, eram avaliados aspectos materiais, de conteúdo, vocabulário e aspectos pedagógicos.

O Golpe de 1964 pôs fim aos debates e avanços educacionais que estavam em curso e mudou os rumos das políticas voltadas aos materiais escolares. Três instituições foram criadas para avaliar e regular a distribuição de livros didáticos: a COTELD $^{10}$, o INL e a Fundação Nacional do Material Escolar (Fename) ${ }^{11}$. A partir de então, o Ministério da Educação (MEC) estabeleceu acordos com a United States Agency for International Development (USaid), ampliando a influência estadunidense não apenas em questões político-econômicas, no contexto da Guerra Fria, mas também educacionais.

Durante a Ditadura Militar e Empresarial, uma análise feita por Faria (2008) demonstra que dentre 35 títulos de livros, dos quais os mais vendidos em 1977, da $2^{\mathrm{a}}$ à $4^{\mathrm{a}}$ série do $1^{\circ}$ Grau das disciplinas de "Comunicação e Expressão", "Estudos Sociais" e "Educação Moral e Cívica", constituíam-se em veículos utilizados pela escola para a transmissão da ideologia burguesa. Para ela:

A educação na sociedade capitalista tem a escola como um dos instrumentos de sua dominação, cujo papel é o de reproduzir a sociedade burguesa, através

8 O Inep foi criado em 1937 com o objetivo de desenvolver estudos e pesquisas na área educacional e, assim, subsidiar os trabalhos do Ministério da Educação. Atualmente, ele recebe a denominação de Anísio Teixeira, que esteve à frente desse Instituto de 1952 até 1964.

9 Acordo feito entre a CALDEME e James Braga Vieira da Fonseca, especialista em ensino de História e Geografia, professor das Faculdades de Filosofia da Universidade Católica do Rio de Janeiro e da Universidade do Brasil (Filgueiras, 2011, p. 115).

10 Criada pelos decretos no 58.653/66 (Brasil, 1966a) e no 59.355/66 (Brasil, 1966b), com a atribuição de "gerir e aplicar recursos destinados ao financiamento e à realização de programas e projetos de expansão do livro escolar e do livro técnico”.

11 Criada pela Lei no 5.327/67 (Brasil, 1967), com o objetivo de produzir e distribuir materiais didáticos para as escolas. 
da inculcação da sua ideologia e do credenciamento, que permite a hierarquia na produção, o que garante maior controle do processo pela classe dominante. (Faria, 2008, p. 12)

Sob domínio da Ditadura Militar e Empresarial, os livros didáticos sofriam fortes interdições. Faria (2008) descreve que eles eram generalistas, simplistas, não falavam de classes sociais, camuflavam a exploração do trabalhador, eram reprodutores de valores moralistas, o homem aparecia como um ser a-histórico e fatos históricos eram omitidos. Naquela época, o Golpe de 1964 era visto como uma revolução, justificada pelas ameaças de greves, revoltas, lutas de classe e discórdia entre os brasileiros. Os índios, selvagens e primitivos; as mulheres, os idosos e os negros, discriminados. Freitag, Motta e Costa (1989) colocam que o ensino nesse período deveria assegurar o desenvolvimento técnico e econômico do país e silenciar as vozes críticas das lideranças politizadas.

Essa visão foi dominante durante décadas nos livros didáticos de Geografia, mesmo antes dessa ditadura. Na apresentação do livro Geografia geral para a segunda série ginasial, escrita em 1952, Azevedo (1960, p. 10), por exemplo, afirma que enquanto a Europa era o "berço" da verdadeira civilização, o continente africano resumia-se a uma paisagem formada de "areias escaldantes e florestas impenetráveis".

Faria (2008) enfatiza que a reprodução da ideologia burguesa não está contida apenas nos livros didáticos por ela analisados. "Assim como não é só a escola que transmite a ideologia da classe dominante, não é só o livro didático que, no seu interior, é responsável por sua veiculação. O próprio professor, com sua postura, seus conhecimentos, pode garantir a sua transmissão" (Faria, 2008, p. 79).

Durante a ditadura, de acordo com Freitag, Motta e Costa (1989, p. 21), não houve, fora o Estado, "outras instituições no Brasil capazes de influenciar, formular e redirecionar o processo decisório sobre o livro didático". Outros importantes atores sociais, como a igreja, as associações científicas, os sindicatos de operários e de professores, as organizações de pais e alunos, as universidades, entre outros, não teriam revelado força suficiente para influenciar essa política de Estado. Até mesmo o mercado editorial se submetia apenas às instruções dadas pelo Estado, definidas por meio de um currículo mínimo.

Na década de 1970, o MEC distribuía, em média, 20 milhões de livros didáticos anualmente, principalmente para escolas carentes, por meio do Plano do Livro Didático do Ensino Fundamental (PLIDEF). A década de 1980 iniciou-se com uma distribuição anual de 30 milhões de livros aos alunos do primeiro grau, chegando aos 50 milhões no final deste decênio, o que representava, naquela época, $50 \%$ da produção nacional de livros.

Freitag, Motta e Costa (1989) apresentam ainda comparações com outros países nesse período. Mesmo nos países da então denominada "Cortina de Ferro" e da própria União Soviética - sob regimes ditatoriais - o Governo Central consultava associações de classe, cientistas e pedagogos. Na Alemanha Ocidental havia comissões mistas, formadas por membros dos governos estaduais de diferentes associações, além de representantes das editoras. No caso dos Estados Unidos, qua- 
tro forças, além do Estado, atuavam na estruturação dos livros didáticos: cientistas, professores, editoras e equipe de autores.

Michel Apple (2002), no entanto, relativiza essa aparente autonomia na elaboração dos livros didáticos estadunidenses. Para ele, "existem pressões de uma variedade de grupos - na sua maioria conservadores - para se definirem quer as formas como os/as professores/professoras ensinam, quer os conhecimentos considerados legítimos para os currículos" (Apple, 2002, p. 77).

A dominação do Estado sobre os conteúdos e métodos dos livros didáticos brasileiros começou a mudar na década de 1980, com o fim do regime Militar e a transição para a democracia, quando vários pesquisadores de universidades paulistas e fluminenses começaram a influenciar o debate sobre os manuais escolares. Na segunda metade dos anos 1980, a Diretoria do Livro Didático da Fundação de Assistência ao Estudante (FAE) indicava uma lista de livros, da qual o professor escolhia o de sua preferência.

Naquele período, Molina (1987), no entanto, já alertava sobre o falso poder de escolha dos professores, uma vez que, para ela, eram as grandes editoras, por meio de uma propaganda maciça e da distribuição de exemplares gratuitos, que determinavam diretamente a escolha do professor. Para essa autora fazia-se necessário preparar o professor para uma escolha criteriosa. Além disso, os livros eram submetidos a avaliações federais e estaduais com comissões formadas exclusivamente por técnicos, assessores e pessoas de confiança política do ministro, muitas vezes pouco familiarizados com a educação.

Alguns problemas das avaliações estatais encontravam-se na dificuldade de elaborar critérios de avaliação adequados, desde os de ordem técnica, como a diagramação e o papel usados para fazer o livro; de fundamentação psicopedagógico; passando pela atualização dos dados até os elementos ideológicos.

Nos anos 1980, apesar de as receitas destinadas para a Educação terem diminuído, os investimentos com livros didáticos aumentaram. Por essa razão, por conta da centralização estatal, muitas vezes as comissões de avaliação assumiam a função de censores do Estado.

São indesejáveis o excesso de centralização (que culmina em censura político-ideológica do LD) quanto uma democratização falsamente compreendida, que atribui ao professor despreparado, sobrecarregado, desmotivado e coagido pelos vendedores das editoras, a tarefa da escolha do livro. (Freitag, Motta e Costa, 1989, p. 49)

Sobre a censura aos livros didáticos, Molina (1987, p. 27) coloca que

países que não exercem praticamente nenhuma censura sobre os meios de comunicação controlam, de forma até severa, os livros didáticos. Em muitos lugares, os livros são fornecidos pelo estado. Isto pode ser, é claro, uma arma de dois gumes, mas tem o mérito de impedir um mercantilismo muitas vezes desenfreado sobre a educação nacional. 
Sobre a centralização do Estado na política de distribuição de livros didáticos, Freitag, Motta e Costa (1989) e Oliveira et al. (1984) apontavam a vulnerabilidade à corrupção, o lobby das editoras e a centralização das decisões que impediriam que outras tendências políticas e ideológicas entrassem em cena, corrigindo distorções, criticando equívocos e propondo alternativas mais eficazes. Para esses autores, seria necessário promover uma maior descentralização da política do LD, com a inclusão dos estados, municípios e das escolas (diretores, professores, pais e alunos).

Nessa época, se discutia a necessária regionalização dos materiais didáticos, alguns defendendo que esse trabalho caberia ao professor, outros pensando em materiais diferenciados para quem vivesse nas periferias urbanas ou em áreas rurais em condições de pobreza. Contudo havia o risco dessa medida reforçar as desigualdades existentes, ao invés de superá-las.

Nas condições de miséria e mediocridade do sistema educacional brasileiro como um todo e do baixo nível de qualificação da maioria dos agentes educacionais (entre diretores, professores e auxiliares de ensino), a regionalização muitas vezes foi sinônimo de improviso e banalização. (Freitag, Motta e Costa, 1989, p. 37)

Com o fim da Ditadura Militar no país, na década de 1980, a política pública voltada ao livro didático passou a ser denominada de Programa Nacional do Livro Didático (PNLD) (Brasil, 1985). Mas foi somente a partir de 1996 que se desenhou o atual modelo, por meio de avaliações consecutivas e da publicação dos Guias de Livros Didáticos.

Esse Programa tem o objetivo de promover a distribuição de manuais escolares a todos os alunos regularmente matriculados nas escolas públicas do país ${ }^{12}$. Para mediar a produção desses materiais e dar a possibilidade de produção de diferentes coleções com correntes teórico-metodológicas próprias, o Ministério da Educação e do Desporto (MEC) instituiu uma avaliação a ser realizada por comissões de professores universitários.

A partir de 1997, o Programa foi ampliado e o Ministério da Educação passou a adquirir, de forma continuada, livros didáticos de Língua Portuguesa, Matemática, Ciências, Estudos Sociais, História e Geografia para todos os alunos de $1^{\text {a }}$ a $8^{\text {a }}$ série do ensino fundamental público. No ano 2000, foi inserida a distribuição de dicionários da Língua Portuguesa; em 2001, iniciou-se o atendimento de alunos com deficiência visual; e em 2003, passou-se a fornecer Atlas Geográficos. Em 2004, foi implantado o Programa Nacional do Livro Didático para o Ensino Médio (PNLEM) que, incialmente, realizou a distribuição de livros de Matemática

12 Todas as escolas beneficiadas estão cadastradas no censo escolar realizado anualmente pelo Instituto Nacional de Estudos e Pesquisas Educacionais Anísio Teixeira (Inep/ MEC). Embora tenham direito, muitos municípios brasileiros adotam sistemas apostilados privados nas suas redes de ensino. Segundo dados da ONG Ação Educativa, em 2013, 339 municípios haviam aderido esse modelo (Adrião, 2016). 
e Língua Portuguesa. Foi somente em 2009, no entanto, que os livros didáticos de Geografia passaram a ser distribuídos aos alunos do Ensino Médio.

Entre 2007 e 2009 foram regulamentados os Programas voltados à Educação de Jovens e Adultos (EJA), intitulados Programa Nacional do Livro Didático para a Alfabetização de Jovens e Adultos (PNLA) e Programa Nacional do Livro Didático para a Educação de Jovens e Adultos (PNLD EJA). Em 2010 foi publicado o Decreto no 7.084, de 27 de janeiro de 2010 (Brasil, 2010), que dispõe sobre os procedimentos para execução dos programas de material didático: o PNLD e o Programa Nacional Biblioteca da Escola (PNBE). O PNLD, dessa forma, deixou de ser uma política de governo para se tornar uma política de Estado. A partir de 2014, algumas coleções didáticas passaram a vir acompanhadas de mídias digitais com conteúdos na categoria audiovisual, jogo eletrônico educativo, simulador e infográfico animado.

Em 2019, o PNLD atendeu 35.177.889 alunos por meio da distribuição de quase 126 milhões de exemplares que custaram pouco mais de 1,1 bilhão de reais aos cofres públicos (Brasil, 2020). Trata-se, portanto, de um grande mercado para as editoras, mas também um profícuo meio de socialização do conhecimento.

A partir de 2016, com a "queda" da presidente Dilma Rousseff e a tomada de poder pelos setores mais conservadores da sociedade brasileira, o debate sobre uma nova Base Nacional Comum Curricular (BNCC) deu lugar a interesses privados de grupos minoritários associados a uma agenda neoliberal. $\mathrm{O}$ Estado vem progressivamente perdendo seu papel central como autor da regulação e os empresários, por meio de fundações, ONGs e instituições filantrópicas, vão protagonizando a formulação de políticas no campo educacional. Conforme Saviani (2014, p. 105):

a força do privado traduzida na ênfase nos mecanismos de mercado vem contaminando crescentemente a esfera pública. É assim que o movimento dos empresários vem ocupando espaços nas redes públicas via Undime e Consed nos Conselhos de Educação e no próprio aparelho do Estado, como o ilustram as ações do Movimento "Todos pela Educação".

Convém destacar ainda que a atuação de agentes externos nacionais e internacionais na formulação de políticas educacionais e na organização curricular é uma prática recorrente no país. Por outro lado, o não envolvimento de professores, alunos e comunidade escolar nesse processo corrobora para sua rejeição tal qual ocorreu com outras políticas prescritivas no campo curricular. $\mathrm{O}$ currículo real se realiza em sala de aula e depende fundamentalmente das decisões tomadas pelo professor. Nesse sentido, qualquer decisão sobre o currículo deve levar em conta a participação ativa do professor.

Em seus fundamentos pedagógicos, a BNCC anuncia que os conteúdos curriculares devem estar a serviço do desenvolvimento de competências. O conhecimento, assim, se legitima em uma perspectiva pragmática, operado e aplicado em situação. A ideia de compreender a realidade de forma crítica buscando a sua transformação se transmuta em desenvolver uma soma de habilidades e competências que o mercado exige dos indivíduos. 
No Ensino Fundamental, a BNCC dividida em tópicos por competências e habilidades apresenta uma estrutura fragmentada que desagrega o saber geográfico. Como exemplo, uma das habilidades impõe que o aluno deverá "analisar os impactos do processo de industrialização na produção e circulação de produtos e culturas na Europa, na Ásia e na Oceania" (Brasil, 2017b), como se fosse possível tratar dessa temática, em um contexto de globalização, excluindo a América e a África. Um evidente retrocesso às décadas de 1940 a 1980, quando a Geografia regional era ensinada na sua forma mais tradicional. No ensino médio, a BNCC se organiza por áreas do conhecimento, no qual o próprio componente curricular Geografia deixou de ser obrigatório. Nesse desmonte, temas da Geografia Física foram sumariamente excluídos e as categorias de análise geográficas foram submetidas a eixos generalizadores dentre as ciências humanas.

Some-se a isso a Lei 13.415/2017 (Brasil, 2017a), que dispõe sobre a Reforma do Ensino Médio, na qual somente Matemática e Língua Portuguesa serão disciplinas obrigatórias nos três anos do Ensino Médio e o fato de a Geografia, assim como outras disciplinas da área de Ciências Humanas, tornarem-se não prioritárias no Programa Institucional de Bolsas de Iniciação à Docência (PIBID) e Residência Pedagógica, em 2020.

Tais mudanças tiveram impactos diretos na produção de livros didáticos. No edital do PNLD 2020, por exemplo, as coleções didáticas voltadas aos anos finais do Ensino Fundamental que "não contribuírem adequadamente para o desenvolvimento de todas as competências gerais e específicas das áreas de conhecimento, constantes na BNCC" (Brasil, 2018) serão excluídas das escolas brasileiras durante pelo menos quatro anos. E, a partir do PNLD de 2021 (Brasil, 2019), os livros didáticos de Geografia deixam de existir nesse nível de ensino, passando a integrar parte de um conjunto de materiais de Ciências Humanas e Sociais Aplicadas, divididos em uma obra didática contendo "projetos integradores" e uma coleção de seis livros.

\section{PARA FINALIZAR}

Sujeito a uma diversidade de sentidos, o currículo é um território de disputas que envolve diferentes concepções de educação e visões de mundo que referenciam o processo educativo. O discurso e a construção curricular no mundo e no Brasil se deram a partir de distintas perspectivas ideológicas com influência de tendências, objetivos e interesses diferentes. Nesse sentido, é importante não desvincular a construção do currículo do contexto histórico e social do país e das injunções das agências internacionais.

O livro didático se constitui como uma mercadoria e muitas vezes objeto de críticas, sobretudo considerando a centralidade desse tipo de texto na consecução do currículo, o que pode perpetuar a clássica dependência do professor, reservando-lhe um papel de mero manipulador e reprodutor de manuais. Por outro lado, as afirmações sobre a importância do livro didático na melhoria da qualidade da educação podem se efetivar principalmente quando o professor estabelece com ele uma convivência produtiva num constante diálogo com a realidade. A Geografia tem um importante papel nesse processo, apoiando o aluno a refletir sobre o mundo 
enquanto sujeito-cidadão atuante e, nesse sentido, é fundamental sua permanência no currículo da escola básica.

De toda forma, as políticas públicas relativas ao livro didático têm propiciado o acesso amplo a esse tipo de material que se constitui, para muitos alunos, como único texto disponível em um universo em que o livro não faz parte dos elementos culturais de muitas famílias. A sua ausência e fragmentação, com as atuais políticas públicas educacionais, deverá produzir um enorme vácuo nessa área de conhecimento considerada estratégica para formação de cidadãos críticos e atuantes.

\section{REFERÊNCIAS}

ADRIÃO, T. Sistemas de ensino privado na educação pública brasileira: consequências da mercantilização para o direito à educação. Ação Educativa, Greppe, 2016. Disponível em: http://acaoeducativa.org.br/wp-content/uploads/2016/10/ sistemas_privados_pt.pdf. Acesso em: 25 jan. 2017.

APPLE, M. W. Manuais escolares e trabalho docente: uma economia política das relações de classe e de gênero na educação. Lisboa: Didáctica, 2002.

APPLE, M. W. Ideologia e currículo. Porto Alegre: Artmed, 2006.

AZEVEDO, A. Geografia Geral: segunda série ginasial. São Paulo: Nacional, 1960.

BARRETO, E. S. S. Tendências recentes do currículo do ensino fundamental no Brasil. In: BARRETO, E. S. S. (Org.). Os currículos no ensino fundamental para as escolas brasileiras. Campinas: Autores Associados, 1998.

BERNSTEIN, B. La estrutura del discurso pedagógico: clases, códigos y control. Madri: Ediciones Morata, 1993. v. 4.

BITTENCOURT, C. M. F. Autores e editores de compêndios e livros de leitura (1810-1910). Educação e Pesquisa, São Paulo, v. 30, n. 3, p. 475-491, 2004. https:// doi.org/10.1590/S1517-97022004000300008

BITTENCOURT, C.M.F.Livros didáticos entre textos e imagens.In:BITTENCOURT, C. (Org.). O saber histórico na sala de aula. 11. ed. São Paulo: Contexto, 2010. p. 69-90.

BRASIL. Decreto-Lei no 1.006, de 30 de dezembro de 1938, que estabelece as condições de produção, importação e utilização do livro didático. Diário Oficial da União, Rio de Janeiro, p. 277, 5 jan. 1939. Disponível em: https://www2.camara.leg.br/legin/fed/ declei/1930-1939/decreto-lei-1006-30-dezembro-1938-350741-publicacaooriginal1-pe.html. Acesso em: 3 fev. 2021.

BRASIL. Decreto no 58.653, de 16 de junho de 1966, que institui no Ministério da Educação e Cultura a Comissão do Livro Técnico e do Livro Didático. Diário Oficial da União, Brasília, Seção 1, p. 6.603, 20 jun. 1966a. Disponível em: https://www2. camara.leg.br/legin/fed/decret/1960-1969/decreto-58653-16-junho-1966-378849publicacaooriginal-1-pe.html. Acesso em: 4 fev. 2021.

BRASIL. Decreto no 59.355, de 4 de outubro de 1966, que institui no Ministério da Educação e Cultura a Comissão do Livro Técnico e do Livro Didático (COLTED). Diário Oficial da União, Brasília, Seção 1, p. 11.468, 5 out. 1966b. Disponível em: 
https://www2.camara.leg.br/legin/fed/decret/1960-1969/decreto-59355-4-outubro1966-400010-publicacaooriginal-1-pe.html. Acesso em: 4 fev. 2021.

BRASIL. Lei no 5.327, de 2 de outubro de 1967, que autoriza o Poder Executivo a instituir a Fundação Nacional de Material Escolar. Diário Oficial da União, Brasília, Seção 1, p. 10.007, 3 out. 1967. Disponível em: https://www2.camara.leg.br/legin/ fed/lei/1960-1969/lei-5327-2-outubro-1967-359134-publicacaooriginal-1-pl.html. Acesso em: 4 fev. 2021.

BRASIL. Decreto no 91.542, de 19 de agosto de 1985. Institui o Programa National do Livro Didático e endereça sua execução e outras medidas. Diário Oficial da União, Brasília, Seção 1, p. 12178, 20 ago. 1985.

BRASIL. Decreto $\mathrm{n}^{\circ} 7.084$, de 27 de janeiro de 2010, que dispõe sobre os programas de material didático e dá outras providências. Diário Oficial da União, Brasília, Seção 1, Edição Extra, p. 3, 27 jan. 2010.

BRASIL. Lei Federal no 13.415, de 16 de fevereiro de 2017. Altera as Leis $n^{\circ}$ 9.394, de 20 dez. 1996, que estabelece as diretrizes e bases da educação nacional, e no 11.494, de 20 jun. 2007, que regulamenta o Fundo de Manutenção e Desenvolvimento da Educação Básica e de Valorização dos Profissionais da Educação, a Consolidação das Leis do Trabalho - CLT, aprovada pelo Decreto-Lei no 5.452, de $1^{\circ}$ maio 1943, e o Decreto-Lei no 236, de 28 fev. 1967; revoga a Lei no 11.161, de 5 ago. 2005; e institui a Política de Fomento à Implementação de Escolas de Ensino Médio em Tempo Integral. Diário Oficial da União, Brasília, Seção 1, p. 1, 17 fev. 2017a.

BRASIL. Ministério da Educação. Secretaria da Educação Básica. Base Nacional Comum Curricular. Brasília: Ministério da Educação, 2017b. Disponível em: http:// basenacionalcomum.mec.gov.br/\#/site/inicio. Acesso em: 4 out. 2018.

BRASIL. Ministério da Educação. Secretaria da Educação Básica. Fundo Nacional de Desenvolvimento da Educação (FNDE). Edital de convocação para o processo de inscrição e avaliação de obras didáticas e literárias para o PNLD 2020. Diário Oficial da União, Brasília, Seção 3, p. 31, 28 mar. 2018.

BRASIL. Ministério da Educação. Secretaria da Educação Básica. Fundo Nacional de Desenvolvimento da Educação (FNDE). Edital de convocação para o processo de inscrição e avaliação de obras didáticas e literárias para o PNLD 2021. Diário Oficial da União, Brasília, Seção 3, p. 62, 13 dez. 2019.

BRASIL. Ministério da Educação. Secretaria de Educação Básica. Fundo Nacional de Desenvolvimento da Educação. Dados do Programa Nacional do Livro Didático. Brasil: Ministério da Educação, 2020. Disponível em: https://www.fnde.gov.br/index. php/programas/programas-do-livro/pnld/dados-estatisticos. Acesso em: maio 2019.

CHEVALLARD, Y. La transposición didáctica: del saber sabio al saber enseñado. La Argentina: Pensée Sauvage, 1991.

CHOPPIN, A. História dos livros e das edições didáticas: sobre o estado da arte. Educação e Pesquisa, São Paulo, v. 30, n. 3, p. 549-566, 2004. https://doi.org/10.1590/ S1517-97022004000300012

ECO,U.; BONAZZI, M. Mentiras que parecem verdades. São Paulo: Summus, 1980. 
FARIA, A. L. G. Ideologia no livro didático. 16. ed. São Paulo: Cortez, 2008. FERREIRA, R. C. A Comissão Nacional do Livro Didático durante o Estado Novo (1937-1945). 2008. 139f. Dissertação (Mestrado em História) - Faculdade de Ciências e Letras de Assis, Universidade Estadual Paulista, Assis, 2008.

FILGUEIRAS, J. M. Os processos de avaliação de livros didáticos no Brasil (19381984). 2011. 263f. Tese (Doutorado em Educação) - Pontifícia Universidade Católica, São Paulo, 2011.

FREITAG, B.; MOTTA, V. R.; COSTA, V.F. O livro didático em questão. São Paulo: Cortez/Autores Associados, 1989.

GONÇALVES, R. C. Comissão de Seleção de Livros Didáticos (1935-1951): guardiã e censora da produção didática. 2005. 163f. Dissertação (Mestrado em Educação) Pontifícia Universidade Católica, São Paulo, 2005.

JACKSON, P. Life in classrooms. New York: Holt, Rinehart e Winston, 1968.

KRAFZIK, M. L. A. Acordo MEC/USAID - A Comissão do Livro Técnico e do Livro Didático - COLTED (1966-1971). 2006. 151f. Dissertação (Mestrado em Educação) - Universidade do Estado do Rio de Janeiro, Rio de Janeiro, 2006.

MOLINA, O. Quem engana quem: professor $\times$ livro didático. Campinas: Papirus, 1987. MOREIRA, R. O discurso do avesso, para a crítica da geografia que se ensina. São Paulo: Contexto, 2014.

MUNAKATA, K. Produzindo livros didáticos e paradidáticos. 1997. 223f. Tese (Doutorado em História e Filosofia da Educação) - Pontifícia Universidade Católica, São Paulo, 1997.

MUNAKATA, K. O livro didático como mercadoria. Pro-Posições, Campinas, v. 23, n. 3 (69), p. 51-66, set./dez. 2012. https://doi.org/10.1590/S0103-73072012000300004 OLIVA, J. T. Ensino de Geografia: um retardo desnecessário. In: CARLOS, A. F. A. (org.). A geografia na sala de aula. São Paulo: Contexto, 1999. p. 34-49.

OLIVEIRA,J. B. A. et al.A política do livro didático. São Paulo: Summus; Campinas: Editora da Unicamp, 1984.

QEdu. QEdu: Aprendizado em Foco. QEdu. Disponível em: http://www.qedu.org. br/brasil/pessoas/professor. Acesso em: 4 dez. 2013.

REDAÇÃO. Só metade dos professores no Brasil tem formação em todas as áreas que lecionam. Esquerda Diário, 23 jan. 2017. Disponível em: https://esquerdadiario. com.br/So-metade-dos-professores-no-Brasil-tem-formacao-em-todas-as-areas-quelecionam. Acesso em: 3 fev. 2021.

SACRISTÁN, G. O currículo, os conteúdos de ensino ou uma análise prática? In: SACRISTÁN, G.; GOMEZ, A. I. P. Compreender e transformar o ensino. Porto Alegre: Artmed, 1998. p. 119-148.

SAVIANI, D. Sistema Nacional de Educação e Plano Nacional de Educação. Campinas: Autores Associados, 2014.

SENE, J. E. O livro didático como produto da geografia escolar: obra menor? Revista Brasileira de Educação Geográfica, Campinas, v. 4, n. 7, p. 27-43, jan./jun. 2014. 
SILVA, T.T. Documentos de identidade: uma introdução às teorias do currículo. Belo Horizonte: Autêntica, 2003.

THOMPSON, J. B. Ideologia e cultura moderna: teoria social crítica na era dos meios de comunicação de massa. Petrópolis: Vozes, 1990.

\section{SOBRE OS AUTORES}

Márcio Abondanza Vitiello é doutor em educação pela Universidade de São Paulo (USP). Professor da Universidade Federal de Alfenas (UNIFAL). E-mail:marcioavitiello@gmail.com

Núria Hanglei Cacete é doutora em geografia física pela Universidade de São Paulo (USP). Professora da mesma instituição. E-mail: nuriah@usp.br

Conflitos de interesse: Os autores declaram que não possuem nenhum interesse comercial ou associativo que represente conflito de interesses em relação ao manuscrito.

Financiamento: Coordenação de Aperfeiçoamento de Pessoal de Nível Superior.

Contribuições dos autores: Escrita - Primeira Redação: Vitiello, M.A.; Cacete, N.H.

Recebido em 4 de março de 2020 Aprovado em 30 de julho de 2020 